\title{
Treatment Response of Opium Smoking Hmong Refugees to Methadone Maintenance
}

\author{
Muhammad Waqar Azeem M.D. \\ Children's Hospital Boston, Harvard Medical School, Boston, MA
}

Gregory A. Carlson B.A.

Hennepin County Medical Center, Minneapolis, MN

Chomehanh Soudaly LPN

Hennepin County Medical Center, Minneapolis, MN

Follow this and additional works at: https://jdc.jefferson.edu/jeffjpsychiatry

Part of the Psychiatry Commons

Let us know how access to this document benefits you

\section{Recommended Citation}

Azeem, Muhammad Waqar M.D.; Carlson, Gregory A. B.A.; and Soudaly, Chomehanh LPN (2002)

"Treatment Response of Opium Smoking Hmong Refugees to Methadone Maintenance," Jefferson Journal of Psychiatry. Vol. 17 : Iss. 1 , Article 2.

DOI: https://doi.org/10.29046/JJP.017.1.001

Available at: https://jdc.jefferson.edu/jeffjpsychiatry/vol17/iss1/2

This Article is brought to you for free and open access by the Jefferson Digital Commons. The Jefferson Digital Commons is a service of Thomas Jefferson University's Center for Teaching and Learning (CTL). The Commons is a showcase for Jefferson books and journals, peer-reviewed scholarly publications, unique historical collections from the University archives, and teaching tools. The Jefferson Digital Commons allows researchers and interested readers anywhere in the world to learn about and keep up to date with Jefferson scholarship. This article has been accepted for inclusion in Jefferson Journal of Psychiatry by an authorized administrator of the Jefferson Digital Commons. For more information, please contact: JeffersonDigitalCommons@jefferson.edu. 


\title{
Treatment Response of Opium Smoking Hmong Refugees to Methadone Maintenance
}

\author{
Muhammad Waqar Azeem, M.D., ${ }^{1}$ \\ Gregory A. Carlson, BA, ${ }^{2}$ and Chomehanh Soudaly, $\mathrm{LPN}^{3}$
}

\begin{abstract}
Objective: To examine the outcome of methadone maintenance in opium dependent Hmong refugees.

Methods: Medical records were searched for Hmong patients in methadone treatment between 01/1995 and 09/1997. Patient's progress was assessed over nine months.

Results: 44 Hmong patients were found. Data was available on 40 patients, mean age 47.7 years, 33 males 7 females. At admission 100\% met the DSM-IV criteria for Opium Dependence, 75\% Major Depressive Disorder and 68\% PTSD. Patients showed marked improvement by having mostly negative urine drug screens, improvement on Addiction Severity Index and $70 \%$ being highly successful on outcome criteria modified by Drug Abuse Research Project over 9 months.

Conclusions: These findings suggest that opium dependent Hmong patients can show marked improvement while in methadone maintenance program. Prospective controlled studies are warranted.
\end{abstract}

\section{INTRODUCTION}

Opium addiction is common in certain Asian populations. Among the fourteen countries with serious narcotic problems, six are in Southeast Asia (1). The prevalence rates of opiate addiction in Southeast Asia is $8-12 \%$ among opium farmers, $6-8 \%$ among groups involved in opium commerce, and 3\% among groups not exposed to opium production or commerce $(2,3)$. The Hmong people in United States were inhabitants of Laos. In Laos the Hmong are considered premier opium

\footnotetext{
${ }^{1}$ Muhammad Waqar Azeem, M.D. is currently a Clinical Fellow in child and adolescent psychiatry at Children's Hospital Boston, Harvard Medical School in Boston, Massachusetts. At the time of this study he was a Chief Resident at Hennepin County Medical Center in Minneapolis and Regions Hospital in Saint Paul, Minnesota.

${ }^{2}$ Gregory A. Carlson is a Director of Addiction Medicine Program at Hennepin County Medical Center in Minneapolis, Minnesota.

${ }^{3}$ Chomehanh Soudaly, LPN is a Hmong Addiction Therapist in Addiction Medicine Program at Hennepin County Medical Center in Minneapolis, Minnesota.

Correspondence should be directed to Muhammad Waqar Azeem, M.D., Dept. of Psychiatry, Fegan 8, Children's Hospital Boston, 300 Longwood Ave., Boston, MA 02115. Phone 617-3556000 .
} 
farmers who cultivate opium for financial benefit and where opium can be found in almost every home $(4,5)$. Treatment of opium addiction in Laos consists primarily of detoxification $(6,7)$. Rates of long term abstinence following treatment are unknown.

Since 1970 more than 166,000 Hmong refugees have migrated to the USA from the refugee camps in Thailand. Large populations have settled in California, Minnesota, Colorado and Washington. Currently, there are 60,000 Hmong settled in Minnesota creating the largest urban Hmong population in the world (8). Based on rates of addiction in Laos, it is estimated that at least $2-5 \%$ of these refugees are regular users of opium. Methadone maintenance is an effective treatment for opioid dependence (9-13), yet little has been reported about the post migration response of opium dependent Hmong refugees to methadone maintenance in the United States.

\section{METHODS}

This is a retrospective study consisting of available data from 40 of the 44 opium dependent Hmong refugees living in Minnesota who were admitted to a hospital based methadone program in Minneapolis between January of 1995 and September of 1997. Patients were rated at admission with translated self-rating scales and interview instruments which included the Symptom Checklist 90 (SCL 90), Hamilton Depression Scale (HAM-D), Hamilton Anxiety Scale (HAM-A), Zung Depression Scale (ZUNG), the Hmong/American Acculturation Scale, the Drug Impairment Rating Scale (DIRS) and the Addiction Severity Index (ASI) (14,15,16,17). In addition, all patients underwent a diagnostic evaluation by a psychiatrist certified by American Society of Addiction Medicine (ASAM). Patients with current psychiatric disorders were provided pharmacotherapy and psychiatric medications were dispersed with their methadone. Urine drug screens were taken randomly, approximately every ten days and tested for the presence of opiates, methadone, amphetamines, barbiturates, cocaine, and benzodiazepines $(18,19)$. Falsification of urine specimens was controlled by direct observation of the patient and specimen temperature measurement (range 91.4-95.2 degrees F.). Patients attended the program daily (Monday through Saturday) and were case managed by a bilingual Hmong staff person with many years of experience as a methadone counselor. ASI scores were reviewed retrospectively for accuracy by the authors.

\section{THE SAMPLE}

During the initial three months, four patients left the program (two relocated out of state, one dropped out unexpectedly, one died due to natural causes) and were not included in this analysis. Forty patients included in the study consisted of 33 men and 7 women. All were self-referred and had been approved for treatment by a community based Hmong service agency. On admission, mean age was 47.7 years (range $(r)=27-86)$. Age of initial opium use was 22.3 years $(r=10-73)$, the total years of using opium three or more times a week averaged 16 years $(r=2-62)$ and mean years in refugee camps was 4.61 years $(r=1-11)$. Opium "Pipes" smoked per day during the month prior to admission averaged $105(\mathrm{r}=25-180)$. 
TABLE 1.

Patient Characteristics

\begin{tabular}{ll}
\hline \multicolumn{1}{c}{ Item } & Mean (Range) N=44 \\
\hline Age & 47.7 years $(\mathrm{r}=27-86)$ \\
Gender & 33 males, 7 females \\
Married & $93 \%$ \\
Employed & $27 \%$ \\
Military service & $77 \%$ \\
Age 1st use & $22.3(\mathrm{r}=10-73)$ \\
Years use & $16(\mathrm{r}=2-62)$ \\
Pipes/day & $105(\mathrm{r}=25-180)$ \\
Number of past treatments & $1.1(\mathrm{r}=0-2)$ \\
\hline
\end{tabular}

$*_{\mathrm{r}}=$ Range.

At admission, $100 \%$ met the DSM IV criteria for opium dependence, $75 \%$ for major depressive disorder, and $68 \%$ for post-traumatic stress disorder (PTSD) (20-23). In addition, Symptom Checklist 90 scores indicated significant psychological distress. Hamilton Depression Scores averaged $28.6(\mathrm{r}=17-44)$, Hamilton Anxiety scores averaged $26.2(\mathrm{r}=16-41)$, Zung Depression scores averaged 40.5 $(\mathrm{r}=22-65)$. The mean Drug Impairment Rating Scale score was $34.1(\mathrm{r}=20-46)$ and Addiction Severity Index Composite score was $3.9(\mathrm{r}=2-7)$. The mean Global Assessment of Functioning (GAF) score at admission was $55.9(\mathrm{r}=40-70)$. The mean scores of the Acculturation Scale (1 low-5 high) for Hmong cultural affiliation was $3.4(r=2-5)$ and for American cultural affiliation was $1.94(r=1-3)(24,25)$. All patients exclusively smoked opium. There was no self-reported use of other drugs or use by injection. All patients were HIV negative. However, $36 \%$ of the patients were Hepatitis C Virus (HCV) antibody reactive (26-28).

\section{RESULTS}

The patients were rated at nine months post admission on number of random urine drug screens positive for other drugs, the Addiction Severity Index, and a

TABLE 2.

\section{Rating Scales: Mean Scores at Admission}

\begin{tabular}{lcc}
\hline \multicolumn{1}{c}{ Instrument } & Mean Score & Range \\
\hline Addiction severity index (ASI) composite & 3.9 & $2-7$ \\
Hamilton anxiety scale & 26.19 & $16-41$ \\
Hamilton depression scale & 28.6 & $17-44$ \\
Zung depression scale & 40.5 & $22-65$ \\
Acculturation scale & & \\
Hmong affiliation & 3.4 & $2-5$ \\
American affiliation & 1.94 & $1-3$ \\
Drug impairment scale & 34.1 & $20-44$ \\
GAF & 56.6 & $40-70$ \\
\hline
\end{tabular}


TABLE 3.

SCL-90 Scores at Admission

\begin{tabular}{ccc}
\hline Symptom Checklist 90 & Mean Score & Range \\
\hline Somatization & 1.9 & $0.8-3.1$ \\
OBS/Compulsive & 2.12 & $0.5-4.0$ \\
Depression & 1.88 & $0.7-3.3$ \\
Anxiety & 1.92 & $0.5-3.2$ \\
Hostility & 1.89 & $0.5-2.7$ \\
Phobic & 1.78 & $0.3-2.9$ \\
Paranoid & 1.88 & $0.5-3.7$ \\
Psychotic & 1.77 & $0.4-2.9$ \\
Additional & 2.05 & $0.7-3.1$ \\
\hline
\end{tabular}

categorical rating system modified on criteria originally established by the Drug Abuse Research Project (DARP).

Of 814 urine specimen tested, 125 (15\%) were positive for other drugs, almost exclusively opiates. The vast majority of the specimens were positive (85\%) during the initial three months of treatment. Each patient averaged 27 urine screens with only four specimens positive during the nine-month period.

The admission ASI ratings were compared to ratings at 9 months post admission (29-32). The student t-test was used to determine statistically significant differences. The most significant improvement occurred in ASI sub scales of employment/ support status changing from 4.4 at admission to 1.5 at nine months $(\mathrm{p}<.01)$, drug use from 8.9 at admission to 4.6 at nine months $(\mathrm{p}<.01)$, family/social relationships from 4.5 at admission to 1.7 at nine months $(p<.01)$, and psychiatric status from 6.2 at admission to 4.5 at nine months $(\mathrm{p}<.01)$. The ASI composite score improved from 3.9 at admission to 1.7 at nine months $(\mathrm{p}<.01)$.

The patient's case manager rated patients status every 90 days according to a categorical rating system modified on criteria originally established by the Drug Abuse Research Project (DARP). At nine months 70\% (28) of patients met criteria

TABLE 4.

ASI Subscale Scores (At Admission and at 9 Months Treatment)

\begin{tabular}{lccc}
\hline \multicolumn{1}{c}{ ASI sub scale } & $\begin{array}{c}\text { Mean at } \\
\text { Admission }\end{array}$ & $\begin{array}{c}\text { Mean at } \\
9 \text { Months }\end{array}$ & $\mathrm{p}<$ \\
\hline Medical status & 2.7 & 2.2 & $\mathrm{~ns}^{*}$ \\
Employment/Support status & 4.4 & 1.5 & $<.01$ \\
Alcohol use & 0 & 0.1 & $\mathrm{~ns}^{*}$ \\
Drug use & 8.9 & 4.6 & $<.01$ \\
Legal status & 0.3 & 0.3 & $\mathrm{~ns}$ \\
Family/Social relationships & 4.5 & 1.7 & $<.01$ \\
Psychiatric status & 6.2 & 4.5 & $<.01$ \\
Composite & 3.9 & 2.1 & $<.01$ \\
\hline
\end{tabular}

*Not significant. 
TABLE 5 .

DARP Criteria Outcomes

\begin{tabular}{lc}
\hline Outcome Category & Percent (N = 40) \\
\hline Highly successful & $70 \%(28)$ \\
Moderately successful & $15 \%(6)$ \\
Moderately unsuccessful & $5 \%(2)$ \\
Highly unsuccessful & $10 \%(4)$ \\
\hline
\end{tabular}

- Highly Successful (HS): No known drug use or positive urine drug screen. Functioning as parent, homemaker, and student. Employed or looking for work. No criminal activity.

- Moderately Successful (MS): Less than 25\% of urinalyses (UAs) positive for other drugs. Generally functioning as parent or homemaker, employed or looking for work. No significant criminal activity.

- Moderately Unsuccessful (MUS): Greater than 25\% but less than $50 \%$ of UAs positive for other drugs. Marginal functioning, not looking for work. May be involved in criminal activity.

- Highly Unsuccessful (HUS): More than 50\% of UAs positive for other drugs. Not functioning as parent, homemaker, and student. Unemployed, not looking for work. Criminal activity.

for being "highly successful", 15\% (6) for "moderately successful", 5\% (2) for "moderately unsuccessful" and 10\% (4) for "highly unsuccessful". At nine months post admission to treatment, the majority of patients had become abstinent from opium and had improved markedly in employment/support status, family and social functioning, and psychiatric status.

\section{DISCUSSION}

The positive response to methadone treatment in this group of patients was due to multiple factors. The most significant change was in the abstinence from opium and improvement in social functioning. The majority of patients improved their employment and support status, family and social functioning, and psychiatric status. The fact that the patients exclusively smoked opium and did not have a history of other drugs and alcohol use including intravenous drug use was likely a significant contributor to the positive outcome. The availability of onsite psychiatric care undoubtedly was also a key factor in the patients overall improvement.

Other factors that likely influenced the positive outcome include involvement of the family/clan in treatment, lack of legal problems, close monitoring for return to opium use and compliance with methadone and psychotropic medications. While the average daily dose among Hmong patients was low (45 mgs) compared to non-Asian patients, the milligram-per-kilogram ratio was not statistically different. As a condition of admission to treatment, the patient's family/clan members played a significant role via regular, two-way communication with the patient's case manager. Family members were encouraged to be supportive of the patient's abstinence from 
opium and to report to the case manager any use of opium or other drugs by the patient. This "therapist/clan" contract is believed to have been an important factor in the positive outcome.

The severity of addiction and addiction related impairment was high, as was the rate of co-occurring psychiatric disorders. The high degree of major depression and PTSD was replication of the previous studies as Kroll et al. (1989) found 80\% prevalence of major depression among the Hmong in a community mental health clinic (33). Similarly Moore et al. (1991) found high rates of PTSD and depression among Mein patients from Laos in their clinic (34). There can be several factors which might have contributed to high rates of PTSD and major depression. The Hmong had either continuous or intermittent traumatic experiences during the war in Laos. Many had years of invasion by the soldiers, with interrogations, threats and indiscriminate killings. Most of them had terrifying escapes from Laos. Often families were separated, as adults and children ran through the jungles in chaos. Many were wounded or killed. Those who succeeded in escaping settled in temporary refugee camps in Thailand that offered extreme crowding and limited food, water, and clothing. Those that managed to migrate to United States faced the further challenges of acculturation, unemployment and poverty.

The high rate of HCV antibody reactivity (36\%) was unexpected given the absence of obvious risk factors. Practices in Southeast Asia such as the reuse of syringes in medical settings and infected blood transfusions may account for the HCV exposure.

While there was significant concern about the potential for diversion of methadone within the Hmong community, this proved not to be a problem. This may be due to an emphasis in educating patients about the responsibilities and risks inherent in take-home methadone and in contracting with patients and clan members to maintain secure storage and medication safety precautions.

The ability to generalize this study to other settings is limited by the small number of patients as well as the range of services not always available in other methadone programs. In this study data for different psychiatric scales regarding depression, anxiety and acculturation was available only on admission. It will be important for the future studies to look at the improvement in these scales prospectively with psychiatric treatment and their relationship with methadone treatment outcome. Other limitation in this study includes lack of comparison group. Future studies should include larger samples with comparison group, multiple sites, and treatment outcome assessed over longer period of time.

\section{REFERENCES}

1. Charassuwanwela Vichaiposhyachinda. Drug use in Asia, Bulletin on Narcotics. Vol. XXXVIII, No. 1\&2, 1986.

2. Westermeyer J, Lyfong T, Westermeyer M, Neider J. Opium addiction among Indochinese refugees in the United States: characteristics of addicts and their opium use. Am J Drug \& Alcohol Abuse 1991; 17:267-277. 
3. Westermeyer $\mathrm{J}$. Opium availability and the prevalence of addiction in Asia. Brit $\mathrm{J}$ of Addiction 1981; 76:85-90.

4. Westermeyer J. Use of alcohol and opium by the Meo of Laos. Amer J Psychiat 1971; 127:8.

5. Westermeyer J, Lyfoung T, Neider J. An epidemic of opium dependence among Asian refugees in Minnesota: characteristics and causes. Brit J of Addiction 1989; 84:785-789.

6. Westermeyer J. Narcotic addiction in two Asian cultures: a comparison analysis. Drug and Alcohol Dep 1977; 2:273-285.

7. Westermeyer J, Peng G. A comparative study of male and female opium addicts among the Hmong (Meo*). Brit J of Addiction 1978; 73:181-187.

8. Minnesota office of Refugee Resettlement, Minnesota Department of Human Services. June 2000.

9. Fiellin DA, O'Connor PG, Chawarski M, Pakes JP, Pantalon MV, Schottenfeld RS. Methadone maintenance in primary care: a randomized controlled trial. JAMA 2001; 286(4):1724-1731.

10. Gossop M, Marsden J, Stewart D, Treacy S. Outcomes after methadone maintenance and methadone reduction treatments: two year follow-up results from the National Treatment Outcome Research Study. Drug \& Alcohol Dependence 2001; 62(3):255-264.

11. Appel PW, Joseph H, Kott A, Nottingham W, Tasiny E, Habel E. Selected in-treatment outcomes of long-term methadone maintenance treatment patients in New York State. Mount Sinai J of Medicine 2001; 68(1):55-61.

12. Stimmel B. Maintenance therapy for opioid addiction with methadone, LAAM and Buprenorphine: the emperor's new clothes phenomenon. J of Addictive Diseases 2001; 20(4):1-5.

13. Chatham LR, Hiller ML, Rowan-Szal GA, Joe GW, Simpson DD. Gender differences at admission and follow-up in a sample of methadone maintenance clients. Substance Use \& Misuse 1999; 34(8):1137-1165.

14. Westermeyer J. Two self-rating scales for depression in Hmong refugees. J of Psychiatric Research 1986; 20(2):103-113.

15. Hamilton M. A rating scale for depression. J Neurol Neurosurg Psychiatry 1960; 23:56-62.

16. Hamilton M. A development of a rating scale for primary depressive illness. Br J Soc Clin Psychol 1967; 6:278-296.

17. Hamilton M. The assessment of anxiety states by rating. Br J Med Psychol 1959; 32:50-55.

18. Chutuape MA, Silverman K, Stitzer ML. Effects of urine testing frequency on outcome in a methadone take-home contingency program. Drug \& Alcohol Dependence 2001; 62(1): $69-76$.

19. Saxon AJ, Calsyn DA, Wells EA, Stanton VV. The use of urine toxicology to enhance patient control of take-home doses in methadone maintenance: effects on reducing illicit drug use. Addiction Research 1998; 6(3):203-214.

20. American Psychiatric Association. Diagnostic and Statistical Manual of Mental Disorders, 4th ed. Washington, DC, American Psychiatric Association, 1994.

21. Brooner RK, King VL, Kidorf M, Schmidt CW, Bigelow GE. Psychiatric and substance use comorbidity among treatment seeking opioid abusers. Arch Gen Psychiatry 1997; 54:7180 .

22. Milby JB, Sims MK, Khuder S, Schumacher JE, Huggins N, McLellan AT, Woody G, Hass N. Psychiatric comorbidity: prevalence in methadone maintenance treatment. Am J Drug \& Alcohol Abuse 1996; 22:95.

23. Moore LJ, Boehlein JK. Treating psychiatric disorders among Mien refugees from highland. Social Science \& Medicine 1991; 32(9):1029-1036.

24. Westermeyer J, Neider J, Callies A. Psychosocial adjustment of Hmong refugees during 
their first decade in the United States. A longitudinal study. J of Nervous \& Mental Disease 1989; 177(3):132-139.

25. Westermeyer J, Neider J, Vang TF. Acculturation and mental health: a study of Hmong refugees at 1.5 and 3.5 years postmigration. Soc Sci Med 1984; 18:87-93.

26. McCarthy JJ, Flynn N. Hepatitis C in methadone maintenance patients: prevalence and public policy implications. J Addict Diseases 2001; 20(1):1-7.

27. Novick DM. The impact of hepatitis $\mathrm{G}$ virus infection on methadone maintenance treatment. Mount Sinai J Medicine 2000; 67(5-6):437-443.

28. Chamot E, de Saussure P, Hirschel B, Delgon JJ, Perrin LH. Incidence of hepatitis C, hepatitis B and HIV infections among drug users in a methadone-maintenance program. AIDS 1992; 6(4):430-431.

29. Bovasso GB, Alterman AI, Cacciola JS, Cook TG. Predictive validity of the Addiction Severity Index's composite scores in the assessment of 2-year outcomes in a methadone maintenance population. Psychology of Addictive Behaviors 2001; 15(3):171-176.

30. Alterman AI, Bovasso GB, Cacciola JS, McDermott PA. A comparison of the predictive validity of four sets of baseline ASI summary indices. Psychology of Addictive Behaviors 2001; 15(2):159-162.

31. Kosten TR, Rounsaville BJ, Klebler HD. Concurrent validity of the Addiction Severity Index. J Nerv Ment Dis 1983; 171:606-610.

32. McLellan AT, Luborsky L, Woody GE, O'Brien CP. An improved diagnostic evaluation instrument for substance abuse patients: The Addiction Severity Index. J Nerv Ment Dis 1980; 168:26-33.

33. Kroll J, Habenicht M, MacKenzie T. Depression and posttraumatic stress disorder in Southeast Asian refugees. Am J Psychiatry 1989; 146:1592-1597.

34. Moore LJ, Boehnlein JK. Posttraumatic stress disorder, depression, and somatic symptoms in U.S. Mien patients. J of Nervous \& Mental Disease 1991; 179(12):728-733. 